\title{
Competitiveness and Employment in a Small Open Economy
}

\author{
Patrice Pieretti and Arnaud Bourgain \\ University Center of Luxembourg
}

\begin{abstract}
The model developed in this article leads to a reduced form that synthesizes the relevant determinants of job creation in a small open economy. Among these factors, we stress the role of competitiveness that is measured by an indicator taking into account the foreign price sensitiveness of domestic exporters. Our model shows that the stronger the price setting power of domestic firms, the greater the impact of competitiveness on employment is. The model is used to empirically estimate the determinants of job creation over the period 1970-1998, in Luxembourg, a small economy, where employment expanded dramatically during the last decades.
\end{abstract}

- JEL Classifications: J23, F41.

- Key words: Competitiveness, Employment, Labor demand, Small open economy.

\section{Introduction}

Motivated by high unemployment in Europe, many theoretical and empirical studies focusing on the relationship between employment and labor cost have emerged over the past years. These contributions are very important for the understanding of fundamental labor demand mechanisms and may be adapted with interest to the specific features of small open economies.

As a matter of fact, increasing mobility and the growing interdependence of world markets favored by the decline of transport and communication costs (Siebert and Klodt 1998) give increasing relevance to the study of small open

*Corresponding address: Cellule de Recherche en Economie Appliquée (CREA), Tel.: 352466644 632+, Fax: 352466644 633, Email: pieretti@cu.lu or bourgain@cu.lu (C)2003-Center for International Economics, Sejong Institution, All Rights Reserved. 
states where job creation depends dramatically on the international economic environment.

This tendency towards globalization does not mean, however, that small states face exogenous constraints without being able to influence international demand to a certain degree. For instance, improvements in competitiveness translate into increases of international demand if there is sufficient scope for price setting behavior. While it is often supposed that small sized countries are price takers, several studies realized on a disaggregated level (Dockner and Sitz 1986; Naug and Nymoen 1996) show that price taking is not always the rule for small economies. By contrast, other empirical studies with disaggregated data by products find a very high own-price elasticity of export demand facing small Asian countries (Panagariya et al. 2001; Athukorala and Riedel 1996). But even if the small economies cannot affect world prices, they may be able to partially determine export prices if export goods compete internationally with imperfect substitutes (Goldstein and Khan 1985).

The purpose of the paper is to evaluate the determinants of labor absorption in a small open economy. In this context we want to focus on the contribution of competitiveness to domestic job creation. We therefore propose a model integrating a general indicator of competitiveness that takes into account a certain degree of price-setting behavior, in addition to international demand and factor substitution.

One important fact is that a small open economy has to export a large share of domestic production and to import almost all it needs. External competitiveness and overall economic situation are therefore fundamental. Moreover, labor supply is very dependent on human inflows. If cross-border labor and capital are sufficiently mobile, we can suppose very price elastic factor supplies.

According to these assumptions, the model is used to empirically estimate the determinants of job creation over the period 1970-1998, in Luxembourg, a small economy where employment expanded dramatically during the last decades. In this context, the paper tries to evaluate how determinants of competitiveness affect job creation, and especially those, that may be influenced by policy decisionmakers of small open economies.

The analytical framework we use in the paper may also be relevant for other aspects of economic performance (like external trade flows) in small open economies, which have benefited from the international fragmentation production processes (Jones 2000, Arndt and Kierzkowski, 2001) 
The paper proceeds as follows. In section II, we develop a model highlighting the impact of competitiveness in the job creation of a small open economy. From this model we derive a labor equation that serves as empirical framework. Section III presents and discusses the estimated determinants of employment in a small open economy like Luxembourg, devoting special attention to the role of competitiveness. Section IV concludes.

\section{A Model of Employment Determination in a Small Open Economy}

We assume that domestic exporters and foreign firms compete in international markets for goods that are differentiated according to their countries of origin. We therefore suppose that profit-maximizing domestic firms have some control on export prices because they supply country specific goods.

The aim of the model we develop is to derive a labor equation following a traditional framework in a way, but different from it in a major aspect. Some approaches are based on profit maximization under a given output level thus abstracting from possible demand feedback from price (competitiveness) effects (Dormont 1997; Legendre 1997). Studies like those of Barrel et al. (1996) explicitly take into account this competitiveness effect but only under iso-elastic demand conditions.

The novelty of our approach is to introduce a variable own-price elasticity of demand depending on a real exchange rate indicator. It follows that price mark-up on average costs is determined by exporters sensitiveness to foreign prices. The less firms are tied to these prices the more they have scope for price setting. We show that the degree of price behavior is an important determinant of the labor equation we derive from our model.

\section{A. The building blocks}

We assume that the whole domestic production is exclusively exported. This assumption is not too unrealistic if one considers that small open economies have to comply with the rules of international competitiveness. Even if a small state could partly produce non-tradable goods, because of the existence of prohibitive transport costs, one may consider export as the driving force of the economy.

Suppose a representative domestic exporting firm that faces an international demand given by: 


$$
D=D\left(P, e P^{*}, Y^{*}\right)=D\left(\tau, Y^{*}\right) \text { with }^{1} D_{\tau}>0, D_{Y^{*}}>0
$$

The variable $\tau$ represents the real exchange rate given by the ratio $\frac{e p^{*}}{P}$ where $P$ is the domestic export price, $e$ the nominal exchange rate (domestic currency per foreign currency) and $P^{*}$ the price of the foreign competing product expressed in foreign currency. Finally $Y^{*}$ represents the aggregate foreign income expressed in foreign currency.

According to a traditional approach, the demand function (1) can be derived from rational agents who maximize individual welfare under a resource constraint (Goldstein and Khan 1985). Since we assume that demand arises only from foreign agents, we use an aggregate GDP (described as $Y^{*}$ in the demand function) in export markets as the foreign resource (income) variable. We do not exclude that domestic exporters could have some price setting power depending on the own price-elasticity of our foreign demand function $\left(\mu=\frac{D_{P}}{D} P<-1\right)$ and how this elasticity is changing with the real exchange rate. Suppose that exporting firms operate with a constant returns to scale technology. It follows that there are no capacity limits and that the only constraint is due to market conditions i.e. in the way production is limited by foreign demand.

Export output $(Q)$ is produced by the following production function:

$$
Q=A F(K, L)=A L f(k) \text { where } k=\frac{K}{L}
$$

$K$ represents the gross capital stock at constant prices. $L$ is total employment. A represents the total factor productivity that is growing at the exogenous rate $\lambda$ and $k$ is the capital-labor ratio.

Since small open economies are traditionally integrated into larger geographical entities, they are able to attract, relatively to their size, an important volume of cross-border factors like labor and capital. This implies that labor and capital supply functions facing a small economy may be regarded as perfectly elastic.

\section{B. The Model}

The representative firm is supposed to maximize total profit:

$$
\Pi=P(Q) Q-c(w, r, A) Q
$$

The unit cost function $c(w, r, A)$ is increasing with labor $(w)$ and capital $(r)$ ${ }^{1} D_{\tau}$ stands for $\frac{\partial D}{\partial \tau}$ 
costs and decreasing with the total factor productivity $(A)$. The constant returns to scale assumption implies that unit cost is independent from the production level $Q$.

Suppose that domestic supply is entirely determined by foreign demand, which implies that the variable $Q$ can be replaced by $D$. Maximization of (3) with respect to $P$ yields following price equation:

$$
P=M(\mu) c(w, r, A) \text { with } M(\mu)=\frac{\mu}{1+\mu} \text { where } \mu=\frac{D_{P}}{D} P
$$

We now suppose that the absolute value of $\mu$ is a decreasing function of the real exchange rate $\tau=\frac{e p^{*}}{P}$. The reason is that the more $e P^{*}$ exceeds $P$, the easier it will be for firms in the export sector to raise prices, because demand is less sensitive to own-price changes. Therefore we write that $\mu=\mu(\tau)$ with $\mu_{\tau}>0$

The price equation that contains the real exchange rate can be approximated by a log-linear form (Hung, Kim, and Ohno 1993):

$$
P=H\left(\frac{e P^{*}}{P}\right)^{\theta} c(w, r) \text { where } \theta \in[0,+\infty[\text { and } H \text { is an intercept }
$$

Solving with respect to $P$ yields:

$$
P=\alpha\left(e . P^{*}\right)^{\beta} c(w, r)^{1-\beta} 0 \leq \beta \leq 1 \text { with } \beta=\frac{\theta}{1+\theta} \text { and } \alpha=H^{1-\beta}
$$

The exporting firm is a perfect price-taker if $\theta \rightarrow \infty$ (or $\beta \rightarrow 1$ ), and a perfect price-setter if $\theta \rightarrow 0$ (or $\beta \rightarrow 0$ ).

First order conditions of profit maximization yield:

$$
\frac{w}{r}=\frac{f(k)-k f^{\prime}(k)}{f^{\prime}(k)}
$$

By differentiating equation (7) and rearranging we may write:

$$
d k=k \sigma\left(\frac{d w}{w}-\frac{d r}{r}\right)
$$

Where $\sigma$ represents the elasticity of factor substitution.

Since we assumed that $D=Q$, we can deduce:

$$
\frac{d D}{D}=\frac{d Q}{Q}=\frac{d[A L f(k)]}{A L f(L)}
$$


Or more explicitly:

$$
\varepsilon \frac{d \tau}{\tau}+\eta \frac{d Y^{*}}{Y^{*}}=\frac{d L}{L}+\lambda+\frac{f(k)}{f(k)} d k
$$

where $\varepsilon=\frac{D_{\tau}}{D} \tau, \eta=\frac{D_{Y}}{D} Y^{*}$ and $\lambda=\frac{d A}{A}$

Using (8) and (10) we obtain:

$$
\varepsilon \frac{d \tau}{\tau}+\eta \frac{d Y^{*}}{Y^{*}}=\frac{d L}{L}+\lambda \alpha_{K} \sigma\left(\frac{d w}{w}-\frac{d r}{r}\right)
$$

where $\alpha_{K}=\frac{f^{\prime}(k) k}{f(k)}$ is the capital share

Solving with respect to the rate of growth in employment we get:

$$
\frac{d L}{L}=\varepsilon\left[\frac{d\left(e P^{*}\right)}{e P^{*}}-\frac{d P}{P}\right]+\eta \frac{d Y^{*}}{Y^{*}}-\alpha_{K} \sigma\left(\frac{d w}{w}-\frac{d r}{r}\right)-\lambda
$$

According to (5) we can write:

$$
\frac{d P}{P}=\beta \frac{d\left(e P^{*}\right)}{e P^{*}}+(1-\beta) \frac{d c}{c}
$$

Equation (12) finally becomes:

$$
\frac{\lambda L}{L}=\varepsilon(1-\beta)\left[\frac{d\left(e P^{*}\right)}{e P^{*}}-\frac{d c}{c}\right]+\eta \frac{d Y^{*}}{Y^{*}}-\alpha_{K} \sigma\left(\frac{d w}{w}-\frac{d r}{r}\right)-\lambda
$$

\section{Competitiveness and Employment}

In this section we want to explicit the link between competitiveness and labor demand implicitly contained in equation (14).

The indicators that appear most frequently in competitiveness assessment are real exchange rates using either consumer price or unit labor costs (Marsh and Tokarich 1996; Agenor 1997). The indicator contained in expression (14) and suggested by Mathis et al. (1988) is defined by the ratio $I=\frac{e . P^{*}}{c}$. It compares exogenous international prices measured in domestic currency $e P^{P^{*}}$ with domestic unit factor costs $(c)$. Note that the greater the gap between $e P^{*}$ and $c$, the higher domestic competitiveness. 
An important feature of the indicator is that it may be decomposed in the following multiplicative manner:

$I=M \cdot R$, where $M=\frac{P}{c}$ is a price mark-up ratio and $R=\frac{e P^{*}}{P}$ the real exchange rate

The indicator $I$ that combines cost- and price-based measures of competitiveness offers some advantages.

First, it only contains variables treated as exogenous in our model.

Secondly, the way changes in $e P^{*}$ (affecting the indicator $I$ ) are transmitted to $M$ and $R$ is indicative of the sensitiveness of domestic firms to world prices and hence about the degree of their price setting power. To show why, consider the polar cases where domestic exporters are either full price takers or perfect price setters. In the first case, changes in $I$ are fully transmitted to $M$ because domestic prices are exactly set at world prices $(R=1)$. In the second case changes in $I$ translate exactly into changes in $R$ because home producers are by definition fully insensitive to foreign price movements.

For mixed cases where exporters are only partial price setters we can formally show from equation (6) that the decomposition of a shock affecting $I$ depends on the factor $\beta$ that measures the domestic sensitiveness to world prices:

$$
R=\alpha \cdot I^{1-\beta} \text { and } M=\frac{1}{\alpha} \cdot I^{\beta} \text { where } \alpha=H^{1-\beta}, M=\frac{P}{c}, R=\frac{e P^{*}}{P}
$$

We are now able to formally precise the impact of competitiveness on job creation by reconsidering equation (14) after expressing the indicator I in percentage changes:

$$
\frac{d L}{L}=\varepsilon(1-\beta) \frac{d I}{I}+\eta \frac{d Y^{*}}{Y^{*}}-\alpha_{K} \sigma\left(\frac{d w}{w}-\frac{d r}{r}\right)-\lambda
$$

Equation (15) is a reduced form of our model stressing the labor determinants, which are relevant in a small open economy. The first term on the right-hand side measures the impact of domestic competitiveness on employment. Note that the higher the price-setting power of domestic exporters is $(\beta \rightarrow 0)$, the closer the elasticity of job creation with respect to competitiveness $\varepsilon(1-\beta)$ is to $\varepsilon$. The reason is that, the more there is scope for domestic price setting behavior, the more increased competitiveness will lead to international demand improvements. The second term in the second part of (15) measures the labor sensitiveness to the international economic situation captured by the elasticity coefficient $\eta$. The third 
term in the right-hand side of equation (15) describes the substitution effect resulting from possible factor price changes. Finally, the last term $\lambda$ represents labor saving technical progress.

Decomposing $\frac{d I}{I}$ and applying Shephards lemma to the unit cost function ${ }^{2} c(w$, $r, A)\left(\right.$ so $^{3} c_{w}=l$ and $c_{r}=\kappa$ where $l=$ labor demand/output ratio and $\kappa=$ capital demand/output ratio) gives following expression:

$$
\frac{d I}{I}=\frac{d\left(e P^{*}\right)}{e P^{*}}-\frac{d c}{c}=\frac{d\left(e P^{*}\right)}{e P^{*}}-\frac{c_{w} d w+c_{r} d r}{c}=\frac{d\left(e P^{*}\right)}{e P^{*}}-\alpha_{L} \frac{d w}{w}-\alpha_{K} \frac{d r}{r}
$$

where $\alpha_{L}=\frac{w \cdot l}{c}$ and $\alpha_{K}=\frac{r \cdot \kappa}{c}$ are respectively shares of labor and capital in total costs.

Equations (15) and (15') can now be used to give a complete description of how a ceteris paribus rise in wage rates $d w / w>0$ negatively influences employment. Two separate effects can thus be identified:

- An international competitiveness effect described by: $-\varepsilon(1-\beta) \alpha_{L} \frac{d w}{w}$, resulting from the change in $I$ induced by the increased wage cost.

- A substitution effect measured by: $-\alpha_{K} \sigma \frac{d w}{w}$.

\section{Empirical application}

Combining equations (15) and (15') and rearranging leads to following empirically testable form:

$$
\frac{d L}{L}=a \cdot \frac{d e p^{*}}{e P^{*}}+b \cdot \frac{d w}{w}+c \cdot \frac{d r}{r}+\eta \cdot \frac{d Y^{*}}{Y^{*}}-(1-\varepsilon(1-\beta)) \cdot \lambda
$$

with: $a=\varepsilon(1-\beta)$

$$
\begin{aligned}
& b=-\varepsilon(1-\beta) \cdot \alpha_{L}-\alpha_{K} \cdot \sigma \\
& c=-\varepsilon(1-\beta) \cdot \alpha_{K}+\alpha_{K} \cdot \sigma
\end{aligned}
$$

Note that the growth rates contained in equation (16) can be roughly expressed as logarithmic differences. By integrating this expression while assuming constancy of the coefficients, we get:

$$
\ln \mathrm{L}=\mathrm{a} \cdot \ln \left(\mathrm{e} \cdot \mathrm{P}^{*}\right)+\mathrm{b} \cdot \ln (\mathrm{w})+\mathrm{c} \cdot \ln (\mathrm{r})+\mathrm{h} \cdot \ln \left(\mathrm{Y}^{*}\right)-(1-\mathrm{e}(1-\mathrm{b})) \cdot \ln (\mathrm{l})+\mathrm{d}
$$

\footnotetext{
${ }^{2}$ The unit cost function is independent of the output level since we assume constant returns to scale. ${ }^{3}$ Where $C_{i}(i=w, r)$ stands for $\frac{\partial c}{\partial i}$
} 
where $d$ is an integration intercept.

We propose to test this labor equation on a small open economy like Luxembourg. This economy has experienced massive job creation during the past fifteen years (see graph 1). Indeed, employment in manufacturing industry and in commercial services widely increased during the period 1975-1998 $:+58 \%$, and $+152 \%$ for commercial services only.

Graph 1: Employment (thousands)

Source: STATEC

Our empirical study concerns only manufacturing and commercial services industries, these branches being the most exposed to international competition. Note that Luxembourg exports the main part of its services since they are overwhelmingly composed of financial products.

In accordance with our model, we assume that costs and wages are exogenous. This assumption is justified in a very small open economy like Luxembourg, since the country is surrounded by a huge (international) regional labor market supplying a large number of cross-border workers (about $35 \%$ of domestic employment). Since this type of labor has no significant impact on land rental prices, wages may be treated as exogenous.

The analysis of the stationarity of the variables on which we regress consists in testing (Augmented Dickey-Fuller test) the null hypothesis of the existence of a unit root against the alternative hypothesis of a stationary process. The tests show that all our variables are non-stationary in level. In first difference, on the other hand we can reject the hypothesis of non-stationarity, leading to test the existence of a relation of cointegration. The ADF test rejects the non-stationarity hypothesis of the static equation residuals. The hypothesis of a long-run cointegration relationship among the explanatory variables is therefore justified. In this case, the coefficients of a model in error correction form can be estimated by ordinary least squares.

Equation (17) can be expressed in a dynamic form with an error correction mechanism. We can thus distinguish between a short and a long run term, where $\mathrm{c}_{7}$ is the error correction coefficient:

$$
\begin{aligned}
\Delta \ln \left(L_{t}\right)=c_{1}+c_{2} \Delta \ln \left(e P^{*}\right)_{t}+c_{3} \Delta \ln \left(Y^{*}\right)_{t} & +c_{4} \Delta \ln (w)_{t} \\
& +c_{5} \Delta \ln (r)_{t}+c_{6} \Delta \ln (T F P)_{t} \\
c_{7} \ln (L)_{t-1}+c_{8} \ln \left(e P^{*}\right)_{t-1}+c_{9} \ln \left(Y^{*}\right)_{t-1} & +c_{10} \ln (w)_{t-1} \\
+ & c_{11} \ln (r)_{t-1}+c_{12} \ln (T F P)_{t-1}
\end{aligned}
$$


This equation has given rise to various regressions. Each of them uses a specific capital user-cost computed with different interest rate variants ${ }^{4}$. These estimations lead to very close and satisfactory results as it appears in Table 1 . In the short-run term, only the statistically significant variables were reported.

In a first attempt, we evaluated foreign income by using foreign added value $\left(Y^{*}\right)$. Unfortunately, this caused autocorrelation in our regression. Therefore, we use $M^{*}$ (imports from the principal partners) in the long-term component as a proxy for foreign purchasing power, which is precisely what foreign income $\left(Y^{*}\right)$ is intended to express. The total factor productivity only appears in the short run dynamic. It has been dropped in the long-run equilibrium because of its strong procyclical (Basu 1996) character and therefore its overstated correlation with employment.

Note that 1995 is the beginning of the new European system of national accounts (ESA 95). This break was effectively captured by a dummy variable in the estimated equations, which passed specification tests for residual

Table 1. Dynamic equations of employment determination Dependent variable: $\Delta \ln \mathrm{L}$

(period: 1971-1998)

\begin{tabular}{|l|c|c|}
\hline \multicolumn{1}{|c|}{ Variables } & Regression 1 & Regression 2 \\
\hline$\Delta \ln \left(\mathrm{eP}^{*}\right)$ & $-0.09(-1.91)^{*}$ & $-0.08(-1.88)^{*}$ \\
$\Delta \ln \left(\mathrm{Y}^{*}\right)$ & $0.38(2.87)^{* * *}$ & $0.38(2.88)^{* * *}$ \\
$\Delta \ln (\mathrm{TFP})$ & $-0.39(-5.52)^{* * *}$ & $-0.37(-5.32)^{* * *}$ \\
Constant & $0.63(4.59)^{* * *}$ & $0.54(3.02)^{* * *}$ \\
$\mathrm{Ln}(\mathrm{L})_{(-1)}$ & $-0.21(-4.02)^{* * *}$ & $-0.18(-3.16)^{* * *}$ \\
$\mathrm{Ln}\left(\mathrm{eP}^{*}\right)_{(-1)}$ & $0.07(3.21)^{* * *}$ & $0.07(3.32)^{* * *}$ \\
$\mathrm{Ln}\left(\mathrm{M}^{*}\right)_{(-1)}$ & $0.17(4.62)^{* * *}$ & $0.16(3.61)^{* * *}$ \\
$\mathrm{Ln}(\mathrm{w})_{(-1)}$ & $-0.08(-3.01)^{* * *}$ & $-0.08(-2.78)^{* *}$ \\
$\mathrm{Ln}\left(\mathrm{r}_{1}\right)_{(-1)}$ & & $-0.03(-1.79)^{*}$ \\
$\mathrm{Ln}\left(\mathrm{r}_{2}\right)_{(-1)}$ & $-0.03(-1.87)^{*}$ & \\
$\mathrm{D} 95$ & $-0.03(-4.83)^{* * *}$ & $-0.03(-4.69)^{* * *}$ \\
\hline $\mathrm{R}^{2}$ & 0.92 & 0.91 \\
DW & 2.07 & 2.14 \\
Test Breusch-Godfrey $(\mathrm{LM})(2)$ & & 0.49 \\
$\mathrm{~F}$ & 0.35 & 0.62 \\
Proba & 0.71 & \\
\hline
\end{tabular}

In parentheses : $t$ statistic.

*** denotes significance at the $1 \%$ level, **: $5 \%$, and *: $10 \%$.

${ }^{4}$ See (data) appendix 
autocorrelation (Breusch-Godfrey LM test ${ }^{5}$ ).

The error correction coefficients obtained are very significant, and equal to only 0.18 and 0.21 . These values indicate a moderate speed of adjustment to the longrun equilibrium, which appears very plausible for employment equations.

By using regression (1), the estimated long-run equilibrium of the dynamic equation of employment determination is given by:

$$
L=\exp ^{3,94} \cdot e P^{* 0,32} \cdot M^{* 0,82} \cdot W^{-0,39} \cdot r^{-0,13}
$$

The signs of these coefficients are consistent with our assumptions. The foreign prices and the international economic situation influence employment positively, and labor costs have a negative impact. Our results show that the user cost of capital has a negative impact on employment, which means that the unit cost effect is higher than the substitution effect.

We will now use our estimation results for calibrating the reduced form (14). This allows us to evaluate the contribution of competitiveness on job creation in Luxembourg.

According to our estimates, the elasticity of $L$ with respect to the competitiveness indicator $I$ is about $\varepsilon(1-\beta)=0.32$. Since our regression is not able to evaluate $\beta$ directly, it has been set equal to 0.75 according to recent estimations (Krecké and Pieretti 1997) about the pricing behavior in the Luxemburg manufacturing sector. This assumption implies that $\varepsilon$ equals to 1.28.

In order to evaluate the factor substitution effect we use the estimated labor-cost coefficient $b$ appearing in equation (16). According to Dormont (1997), frequent errors in measuring capital-costs greatly affect the estimation of factor substitution elasticities $(\sigma)$. It follows that labor-cost coefficients are most appropriate for the estimation of $\sigma$. We thus obtain a coefficient $\sigma$ equal to 0.45 . This value is consistent in magnitude with empirical studies using aggregated data (Hamermesh 1993). From our data we compute an average capital share equal to 0.52 . This share is abnormally high compared with international standards since financial industry is dominant in the Luxembourg economy ${ }^{6}$. The coefficient on the relative factor price term in (16) is thus about -0.23 . In other words, a ten percent increase in wages

\footnotetext{
${ }^{5}$ The Durbin-Watson test for first order serial correlation is also reported, although this statistic is invalidated when lagged of the dependent variable appear on the right hand side

${ }^{6}$ At international level, one observes generally a low labor share in financial industry comparatively to the rest of the economy.
} 
relative to capital-cost induces a labor decrease of 2.3 percent.

Finally, we find a strong impact of overall economic situation on domestic employment $(\eta=0.82)$, which is consistent with the extreme openness of a very small sized economy.

\section{Conclusion}

The model developed in this article yields a reduced form which helps analyzing determinants of employment in a small open economy. Among these factors, we stress the role of competitiveness that is measured by an indicator taking into account the foreign price sensitiveness of domestic exporters. Our model shows that the stronger the price setting power of domestic firms is, the greater the impact of competitiveness on employment will be. Improvements in competitiveness may then have a positive impact on employment through profitability channels but this aspect is not taken into account by the model.

Beside competitiveness, we could also evaluate the effects of overall economic situation and factor-price movements on employment. Our objective however was to focus on the labor determinants that may be endogenously influenced by domestic behaviors. In this context it is worthwhile to consider labor productivity improvements leading to unit cost reductions and measures that favor product differentiation according to the source country which tend to relax the degree of sensitiveness to world price-competition.

The capacity to differentiate according to the source country may not only be tied to private firm decisions but also to the quality of domestic government performances. For advanced economies, globalization will increasingly provide incentives for institutional differentiation strategies and give economic policy a new dimension. This aspect has always been essential for small open economies, which thus deserve a particular attention in the study of competitiveness in a context of global competition.

\section{Acknowledgement}

We would like to thank two anonymous referees for very helpful comments and suggestions on the earlier version.

Received 31 October 2001, Accepted 19 April 2002 


\section{Appendix}

The data for domestic indicators are obtained from STATEC (Statistical Institute of Luxembourg), and the international data are obtained from Eurostat (Newcronos).

$L: \quad$ Employment (number of employees)

$K$ : $\quad$ Gross capital stock at constant prices.

$w$ : Nominal wage rate, compensation of employees at current price divided by L.

$r$ : $\quad$ Cost of capital (nominal), r1 is calculated with private sector bond yields (Luxembourg) and $\mathrm{r} 2$ is an average of this long-term rate and the 3 months money market rate of Belgium.

$P$ : $\quad$ Value-added price index, value-added deflator for manufactured branches and market services.

$P^{*}: \quad$ Value-added price index of seven major trading partners of Luxembourg (Belgium, France, Germany, Italy, Netherlands, United Kingdom, and USA), constructed using the value-added series in constant and current prices, and weighted by the part of each partner in the Luxembourg's imports.

$Y^{*}: \quad$ Value-added index at constant prices of seven major trading partners of Luxembourg (Belgium, France, Germany, Italy, Netherlands, United Kingdom, and USA) weighted by the part of each partner in the Luxembourg's imports.

$M^{*}$ : Imports index at constant prices of seven major trading partners of Luxembourg (Belgium, France, Germany, Italy, Netherlands, United Kingdom, and USA) weighted by the part of each partner in the Luxembourg's imports.

TFP: Total factor productivity. The percentage change of the total factor productivity $(\hat{A})$ can be expressed as follows:

$$
\hat{A}=\hat{y}-\alpha \cdot \hat{k}
$$

In this expression, the first term refers to percentage change in the labor productivity ratio $(\hat{y})$. In the second term, $\alpha$ refers to the capital share in valueadded. $(1-\alpha)$ is calculated as the share of labor in the value-added. $(\hat{k})$ Refers to the percentage change in the capital-labor ratio. 


\section{References}

Agenor, P.R. (1997), "Competitiveness and External Trade Performance of the French Manufacturing Industry," Weltwirtschafliches Archiv, 133(1), 103-133.

Arndt, S.W. and H. Kierzkowski (eds) (2001), Fragmentation : New production Patterns in the World Economy, Oxford: Basil Blackwell.

Athukorala, P. and J. Menon (1995), "Exchange Rates and Strategic Pricing in swedish Manufacturing Export," Oxford Bulletin of Economics and Statistics, 57 (4), 529542.

Athukorala, P. and J. Riedel (1991), "The Small Country Assumption: A Reassessment with Evidence from Korea," Weltwirtschafliches Archiv, 127(1), 138-151.

Barrell, R., Pain, N., and G. Young (1996), "A Cross-Country of Demand for Labor in Europe," Weltwirtschafliches Archiv, 132(4), 638-650.

Basu, S. (1996), "Procyclical Productivity Increasing Returns or Cyclical Utilization," The Quarterly Journal of Economics, 111(3), 719-751.

Dockner, E. and A. Sitz (1986), "An Investigation into Austrian Export Pricing: Price Taking or Price Setting of a Small Open Economy?," Empirica 13(2), 221-241.

Dormont, B. (1997), "Linfluence du coût du travail sur la demande de travail, Economie et Statistique," n 301-302, 95-109.

Goldstein, M. and M. S. Khan (1985), "Income and Price Effects in Foreign Trade," in Jones R.W. and Kenen P. (eds), Handbook of International Economics, Vol II., Amsterdam, North Holland.

Hamermesh, D. (1993), Labor Demand, Princeton, Princeton University Press.

Hung, W., Kim, Y. and K. Ohno K. (1993), "A Pricing Export: A Cross-Country Study," Journal of International Money and Finance, 12, 3-28.

Jones, R. W. (2000), Globalization and the Theory of Input Trade, MIT Press.

Krecké, C. and P. Pieretti (1997), "Degré de dépendance face aux prix étrangers d'un secteur exportateur d'un petit pays: une application à pindustrie luxembourgeoise," Economie Appliquée, L, 153-175.

Layard, R., Nickell, S. and R. Jackman (1991), Unemployment: Macroeconomic Performance and the Labour Market, Oxford, Oxford University Press.

Legendre, F. and P. Le Maitre (1997), "Le lien emploi-coût relatif des facteurs de production : quelques résultats obtenus à partir de données de panel," Economie et Statistique, $\mathrm{n}^{\circ}$ 301-302, 111-127.

Marsh, I., and S. Tokarick (1996), "An Assessment of Three Measures of Competitiveness, Weltwirtschafliches Archiv," 132(4), 700-722.

Mathis, J., Mazier J., and D. Rivaud-Danset (1988), La compétitivité industrielle, Paris: IRES, Dunod.

Naug, B. and R. Nymoen (1996), "Pricing to Market in a Small Open Economy," Scandinavian Journal of Economics, 98(3), 329-350.

Panagariya, A, Shah, S. and D. Mishra (2001), "Demand Elasticities in International 
Trade: Are they Really Low?," Journal of Development Economics, 64, 313-342. Siebert, H. and H. Klodt (1998), "Toward Global Competition: Catalyst and Contraints," Kiel Working Paper n897, December. 